\title{
Challenges in the Management of Congenital Heart Disease in Developing Countries
}

\author{
Fidelia Bode-Thomas \\ University of Jos \\ Nigeria
}

\section{Introduction}

The 2011 World Bank classification of nations and their economies based on 2010 per capita Gross National Incomes (GNI) lists 35 countries as low income (GNI 1005 US Dollars or less), 56 as lower middle income (1006 - 3975 USD), 54 upper middle income (3976 - 12275 USD) and 70 as high income (12,276 USD or more). Low and middle income countries are often conveniently referred to as developing countries (World Bank, 2011) but vary greatly in their levels of economic, infra-structural and health care development. The challenges of managing congenital heart disease in many low income and lower middle income countries are overwhelming, with very few or in some cases no treatment and prevention strategies in place at all. On the other hand, many upper middle income countries and a few lower middle income ones having been able to establish successful programmes for the treatment of congenital heart disease, albeit not without challenges, are striving to extend these services to the under-served parts of their populations while still confronted with challenges of prevention.

Congenital heart disease (CHD) refers to the presence of a structural abnormality of the heart and / or great vessels that is present at birth and is of actual or potential functional significance. The term usually excludes congenital arrhythmias and cardiomyopathies even though these may be based on genetic or other abnormalities that are present at birth (Hoffman \& Kaplan, 2002). In recent decades, the management of congenital malformations of the heart has improved remarkably in the developed world such that even very complicated lesions are now amenable to treatment. The situation in many of the least developed countries / regions is the direct opposite - only very few children born with congenital heart disease ever receive the appropriate treatment or care. This is the result of several factors that may be considered obstacles or challenges to congenital heart disease management in these regions. Thus, hundreds of thousands of children die each year from congenital heart disease, while millions more remain in desperate need of treatment in the developing world. Alleviating the sufferings of such children is a major challenge to practitioners and perhaps even more so to the families of affected children. Several strategies have been advocated and used in attempts to help some of the affected children access the necessary care. These strategies vary from transporting a few affected children to other countries for treatment, to short-term visits by teams of experts from advanced countries to perform surgical procedures on a few children, to establishing regional centres 
of excellence for training and treatment in some developing countries (Stolf 2007, Pezzella 2010). These strategies however are also not without their own inherent challenges. This chapter will highlight some of the peculiarities of management and the practical problems often encountered in the diagnosis, treatment and prevention of congenital heart diseases in the developing world.

\section{Burden of congenital heart disease in developing countries}

There is a paucity of data on the incidence or birth prevalence of congenital heart disease in most developing countries. A few studies from developing countries coupled with a review of several studies from developed countries suggest similar range from country to country and across different time periods (Subramanyan et al., 2000; Khalil et al., 1994; Hoffman \& Kaplan, 2002). However, the reported incidence in developed countries has steadily increased from about 4 to 5 per 1000 live births in the 1950 's to as much as 50 to 75 per 1000 live births more recently - largely due to improved diagnosis using echocardiography which enables the diagnosis of many more trivial lesions than had hitherto been the case (Hoffman \& Kaplan, 2002). The number of children born with congenital heart disease in developing countries have generally been extrapolated (based on the assumption of similar worldwide incidence) by applying rates obtained from older studies in developed countries to estimated numbers of live births in the developing countries and thus the actual figures may be much higher. Indeed, there generally is a paucity of data on the birth prevalence of all congenital malformations from developing countries, so that the impacts of these defects have been systematically underestimated in the past (Howson et al., 2004). These authors have also emphasized the huge public health importance of these disorders and provided more comprehensive extrapolated data than had hitherto been available. They have further highlighted the role of factors such as constrained diagnostic capabilities, poor healthrelated statistics, lack of birth defect surveillance and registries, and over-reliance on hospital-based rather than population-based studies as factors that have contributed to the underestimation of the toll of congenital anomalies in developing countries, where $94 \%$ of birth defects and $95 \%$ of their associated deaths occur. Other factors that have contributed both to the higher proportion of birth defects and their absolute numbers in these countries include their higher birth rates and higher prevalence of risk factors such as higher proportion of older mothers, exposure to environmental teratogens and poverty, which is very often associated with maternal malnutrition and more frequent infections. Congenital cardiac malformations constitute at least one quarter of all birth defects and are among the most severe and life-threatening. It is estimated that 960,000 of the slightly over 1 million children born with CHD worldwide annually are born in low and middle income countries - Table 1 (March of Dimes, 2006).

Because of the paucity of treatment facilities in developing regions and the known fact that without treatment $60 \%$ of congenital heart diseases are lethal within the first two years of life (Adams, 1959), it is also widely recognized that many more children die from congenital heart disease in developing countries compared with the developed. In addition to the deaths that may be directly attributable to heart disease, many children with congenital heart disease also die from some of the infectious diseases of childhood that are so prevalent in the less developed regions of the world. For these reasons, prevalence studies though more readily available in developing countries than incidence studies, tend to underestimate the burden of congenital heart disease (Saxena, 2005), since prevalence is a function both of incidence and 
mortality or survival rates. The disability-adjusted life years (DALYs) lost may give a more accurate picture of the disease burden since this measure takes into account the incidence, mortality as well as the quality of life of those who survive. However, there is a paucity of all these categories of data from developing countries, making it difficult to estimate the true burden of congenital heart disease. What is undisputable is that congenital heart disease in developing countries is associated with a very high mortality rate and that in spite of this, hundreds of thousands more children are added every year to the growing pool of affected children requiring intervention. Estimates of the actual numbers of these children however vary widely. This absence of accurate data constitutes one of the major obstacles to efforts to tackle the problem of congenital heart disease in developing countries as it underrates the problem, hinders planning and undermines arguments for more resource allocation in the face of the many other competing health care needs.

\begin{tabular}{lc}
\hline Country & estimated affected births per year \\
\hline Bangladesh & 33,844 \\
Brazil & 26,568 \\
China & 148,844 \\
DRC* & 19,805 \\
Ethiopia & 22,499 \\
India & 198,385 \\
Indonesia & 35,076 \\
Nigeria & 37,146 \\
Pakistan & 42,166 \\
\hline
\end{tabular}

* Democratic Republic of the Congo

Adapted from: March of Dimes Global Report on Birth Defects, 2006

Table 1. Estimated number of congenital heart disease live births in selected developing countries

\section{Peculiarities and challenges of CHD diagnosis and treatment in developing regions}

Because of the stage of their socio-economic and infrastructural development and the fact that the treatment of congenital heart disease requires specialized centres that are expensive to establish and to maintain, the management of congenital heart disease in developing regions differs in many significant and challenging aspects from what obtains in the developed world. A major contributing factor is that congenital heart disease is usually not considered a priority for resource allocation by policy makers in developing countries (Saxena, 2005). Many such countries and also international donor agencies have been preoccupied by infectious diseases and lack policies on congenital heart disease control and treatment even if under the umbrella of paediatric cardiac diseases and / or congenital malformations (Children's HeartLink, 2007). Some of the major peculiarities of congenital heart disease patients and programmes in developing regions therefore include:

\subsection{Late diagnosis}

Late diagnosis - unlike in developed countries where prenatal diagnosis and neonatal corrective surgery are now the norm, CHD in developing countries are typically diagnosed 
late (Bannerman \& Mahalu, 1998; Saxena, 2005; Mocumbi et al., 2011). The mean age at diagnosis or treatment varies depending on whether the data are from a purely paediatric service or include adults as well and can range from the first day of life to almost 80 years (Bode-Thomas et al., 2003, Mocumbi et al., 2011; Ibadin et al., 2005). As a result, most of the cases seen are those with more 'favourable' lesions that have been 'naturally selected' (Rao, 2007). Some of the reasons for this pattern of late diagnosis have been identified as:

\subsubsection{Late presentation}

Late presentation due to high level of illiteracy in many of these populations, coupled with lack of awareness about health issues generally, but especially about CHD. This is compounded by poverty and lack of access to basic medical care (Children's HeartLink, 2007). Thus the first presentation to hospital or to a specialist may be because of complications.

\subsubsection{Ignorance about CHD even among health workers}

Ignorance about $\mathrm{CHD}$ even among health workers, leading to frequent non-diagnosis or mis-diagnosis with wrong treatment and /or inappropriate counseling (LeBlanc, 2009). Heart disease is often wrongly assumed to be rare or very unlikely in children, so that its index of suspicion among health workers is very low. It is therefore not uncommon for children with CHD to have been treated for various other conditions such as tuberculosis or asthma before being eventually referred to a specialist that makes the correct diagnosis. The parents of a child with tetralogy of Fallot who were both health workers for example, had resigned themselves to his early demise as they were told no definitive treatment existed. He presented to a tertiary centre with endocarditis at 10 years of age and after a turbulent admission eventually had his heart lesion repaired in another country. Though his heart is 'healed', he now suffers from a seizure disorder.

\subsection{Paucity of personnel and facilities for diagnosis and treatment}

These are persistent problems that have been highlighted by many authors. They not only contribute to late diagnosis but also to late treatment if at all diagnosed, or no treatment at all and eventual loss to follow-up. Some of the patients receive palliative medical treatment e.g. for heart failure or propranolol to help reduce the frequency of hypercyanotic attacks in patients tetralogy of Fallot or similar physiology. However, with the absence of health insurance in many countries, the direct and indirect healthcare costs both of routine hospital visits (transportation, medication and loss of man hours) and repeated hospitalizations often result in 'catastrophic health care expenditure' for the families (Sadoh, 2011). As a result, many go into debt, sink further into poverty and/or default from follow-up.

\subsection{High prevalence of complications}

Due to late presentation and lack of treatment coupled with the high prevalence of infections and nutritional deficiencies in many developing communities, patients with congenital heart disease frequently present with such complications as chronic congestive heart failure, severe polycythemia, frequent and severe hypercyanotic attacks, cerebrovascular accidents, malnutrition and infective endocarditis - or develop them in the course of follow-up. These frequently necessitate hospital admissions to treat the complications and are a further drain on family and health system resources. Thus paradoxically, although 
congenital heart diseases are often not considered to be of priority and their treatment usually not budgeted for, they still constitute a huge drain on limited health care resources. The same factors also predispose patients to high rates of surgical complications and mortality in the few available surgical treatment facilities (Rao, 2007; Mocumbi et al., 2011). Channeling these more or less wasted resources into planned care for these children will obviously yield more fruitful results.

\subsection{Emphasis on palliative and closed heart procedures and on "curable" congenital heart lesions}

In some parts of the developing world it is a luxury even to have rudimentary cardiac surgery services. When present these are often plagued by scarce resources including funds, personnel, expertise, equipment and consumables. In some places shortage of electricity and water supplies compound the problems. It is usually necessary to prioritize care and triage patients so that as many children as possible can benefit from the available resources without also undertaking procedures that may constitute an unnecessarily high risk and waste of resources under the circumstances. Therefore cardiac surgery centres in developing regions often place more emphasis on palliative and closed heart procedures especially when just beginning (Rao, 2007; Mocumbi et al., 2011). Even so, in many of the least developed countries, the number of centres that have the capability to undertake these procedures may be very few and far between, so that the few families that can afford them do still have to travel long distances within or even outside their own country. Eventually, only a minority of children that might have benefitted from such procedures are able to do so.

\subsection{Transportation of patients to other countries for treatment}

Apart from the expense, comparatively few children can benefit from this option of treatment compared with the large number affected. It has been described as the worst option because it does not create human and organizational expertise for the country (Stolf, 2007). Also, several challenges have been associated with this alternative. Sometimes in an attempt to help the "neediest" there may be poor patient selection, especially when an inexperienced physician is involved. Very sick, advanced or complicated cases may be selected leading to such problems as:

\subsubsection{Acute complications while airborne}

Acute complications while airborne - such as hypercyanotic attacks. These may necessitate emergency landings. If there is no one on board knowledgeable enough to give the appropriate emergency management, death is a real possibility. Thus some airlines require mandatory medical escorts for such patients - which further increase costs.

\subsubsection{Pre-operative or early operative mortality in the host country}

Pre-operative or early operative mortality in the host country. This creates additional problems such as the need for a distraught parent to decide whether and how to bury the child in a foreign country, or whether to cremate or to transport the corpse back home for burial. Apart from the additional burden on the host organizations/families, this creates immediate and later psycho-social problems for the parents and families of the affected child. 


\subsubsection{Multiple-stage surgeries}

Multiple-stage surgeries - if the patient turns out to have a complex heart lesion that requires 2 or more stages of surgery, decisions will also have to be taken as to whether to send the child back home untreated, perform the first stage of surgery only or commit to bringing the patient back after a few years to perform the subsequent stage(s) of surgery. Whatever decision is taken is associated with great cost either of the treatment or the emotional cost to the family of having to send their child home back untreated.

\subsection{Intermittent cardiac surgery missions}

It has been argued that transporting children to other countries for treatment coupled with intermittent "missions" to existing non-specialist hospitals to carry out cardiac surgery can act as "enabling projects" that help bring the problem into focus while the creation of a sustainable unit is being planned (Yacoub, 2007). Some have however criticized this treatment alternative because only a limited number of patients can be assisted and the results are not consistently satisfactory - since the local hospital conditions are often far from ideal and the team may not be on ground long enough to observe and manage some of the post-operative complications (Stolf, 2007). It is nevertheless a better option than no surgery at all and offers the possibility of training local surgeons and hospital personnel, which should be a major focus (Stolf, 2007; Yacoub, 2007).

\subsection{Establishing treatment centres in developing countries}

The ideal option remains the development or establishment of treatment centres in the developing countries themselves. This is the most challenging option because of the huge investments required - in terms of technology, infrastructure and the training of personnel (cardiologists, surgeons, intensive care personnel and other cardiovascular specialists) . Some of the success stories notably in India and Brazil have been as a result of home-grown efforts coupled in some cases with the efforts of returning citizens trained in developed countries. Others have been spearheaded by humanitarian efforts of individuals and groups from developed countries - notably in China, Vietnam, Mozambique and Guatemala (Pezella, 2010; Yacoub, 2007). It is a daunting task that requires great commitment in view of the tremendous social and economic challenges often encountered. The biggest challenge here is that of sustainability. The presence of home-grown technology (as in India, Brazil), cost-saving measures such as re-sterilizing and re-using consumables, long-term commitment and support from donor organizations in developed countries and incorporating research into the programme appear to be factors that favour sustainability (Rao 2007, Yacoub 2007).

\section{Challenges of congenital heart disease prevention in developing countries}

The prevention of congenital heart disease, like that of any other disease condition hinges on a basic understanding of its causes. There is widespread ignorance and misconception in many developing countries about the aetiology of congenital heart disease and other birth defects. Even in the developed world, it was only in the 20th century that the causes of birth defects including congenital heart disease were clearly categorized into the three broad groups now widely recognized: those originating in the pre-conception period and due primarily to genetic (chromosomal and single gene defects) and partly genetic causes 
(multifactorial inheritance involving interaction of genes and the environment); those arising after conception but before birth (these are usually due to teratogens); and those of unknown cause (Christianson \& Modell, 2004 as cited in March of Dimes 2006).

The majority of CHD are attributable to multi-factorial inheritance which is largely not preventable based on the current state of our knowledge. The risk of chromosomal anomalies however increases with advancing maternal age, so that developing countries have a higher incidence of chromosomal trisomies because of limited access to family planning and a high percentage of pregnant women of advanced maternal age (35 years or older). There is often also deficient or absent prenatal screening, diagnosis, and associated services (Modell et al as cited in March of Dimes 2006; WHO 1996). Down syndrome or trisomy 21, the most common chromosomal disorder is associated with congenital heart disease in about $50 \%$ of cases. Trisomies 18 and 13 are much less common and are each associated with congenital heart disease in over $90 \%$ of cases (Park, 2007).

Teratogen-induced heart defects, though more readily preventable, are more common in developing countries because of higher frequency of intrauterine infection, notably rubella, lack of environmental protection policies, and poorly regulated access to medication (Penchaszadeh, 2002 as cited in Howson et al, 2008). Between 5 and 10\% of birth defects in high income countries are of post-conception origin compared with approximately 10 to 15 $\%$ for developing countries. In countries with successful rubella immunization programs, congenital rubella has been largely eliminated. In the remaining 50 percent of countries, more than 100,000 infants are born with CRS annually (WHO 2000 as cited in March of Dimes, 2006).

Other factors that contribute to the higher burden of congenital heart disease in developing countries include: poverty, which predisposes women to malnutrition before and during pregnancy, and to a greater risk of exposure to environmental teratogens, parental consanguinity - a common practice in some developing countries and inadequate access to health care which hinders the control of some of the risk factors for congenital heart disease (Bassili et al., 2000; Children's HeartLink, 2007).

\section{Reducing the toll of congenital heart disease in developing countries}

The huge toll of congenital heart disease in developing countries obviously calls for urgent action. Management of congenital heart disease in developing countries has hitherto however focused primarily on treatment. While treatment is very important, the huge capital investments necessary to treat affected children and those yet to be born, is clearly beyond the limited health budgets of many developing countries. The need for a paradigm shift in the management of cardiac diseases from treatment only, to prevention plus treatment and rehabilitation has been highlighted (Pezzella 2010). This has implications as well for congenital heart disease, at least those that are clearly preventable and presents the need for paediatric cardiologists to be more involved in efforts to eliminate or minimize the occurrence of congenital heart diseases of preventable cause. Furthermore, the prevention of congenital heart disease would be difficult to separate from that of other birth defects and therefore should be an integral part of prevention strategies for birth defects generally.

Even though religious and socio-cultural differences may not permit the wholesale adoption some of the methods used, there are many lessons to be learnt from the experiences of more developed countries, where the incidence of birth defects have been reduced by about $75 \%$ 
over the last few decades. Some of the steps taken by those countries (Howson et al, 2008) included:

- Improved collection and use of data

- Improved prenatal and peri-natal services including promotion of family planning, rubella immunization before pregnancy and folic acid fortification of commonly consumed foods.

- Training of health care professionals in best practices in care and prevention

- Educating the public on steps to take to promote a healthy pregnancy outcome including avoidance of teratogens during gestation, etc.

The foregoing coupled with the realities on ground in many developing countries today, inform certain broad areas of emphasis, including the urgent need for research and accurate data, improved diagnosis and treatment and a greater emphasis on prevention than has hitherto been the case. Preventive measures in particular deserve high priority and should be integrated into primary health care. As has been suggested, achieving the millennium development goals will also help to reduce the toll of paediatric heart disease, including congenital heart disease in developing countries (Leblanc, 2009). The need for communitybased studies to generate accurate statistics on incidence, mortality and survival and the improved collection of routine data cannot be over-emphasized as such data are vital for planning intervention programmes and to justify more resource allocation. Longer term measures include the provision of more treatment facilities and the training of more specialists - obstetricians, paediatricians, cardiologists, paediatric cardiologists, cardiac surgeons, and all other allied health care professionals. This requires more resource allocation and more judicious use of available resources.

\section{Conclusion}

There is a need to increase public awareness about congenital heart disease in developing countries so as to encourage early presentation and enhance early diagnosis. Equally important is the need to educate all categories of health workers on early detection and referral coupled with prevention measures, including incorporating such teaching into the training curricula of the various categories of health workers. The need for good quality data and the training of more specialists so as to enhance treatment of affected children cannot be over-emphasized. Even though capital intensive, the need to provide more treatment centres for affected children can also not be avoided indefinitely. These measures require that health policymakers be made aware of the extent of the problem so that more resources can be allocated for primary level care which includes prevention, early detection and referral; secondary level care including medical treatment of some complications and tertiary care which includes surgical repair and rehabilitation. All these measures need to be complemented by research into local incidence and risk factors, and support from international agencies.

\section{References}

[1] Adams, F. (1959). Congenital heart disease: comments regarding incidence and natural history. California Medicine, Vol. 90, No. 3, (March 1959), pp. 213-216

[2] Bannerman, C. and Mahalu, W. (1998). Congenital heart disease in Zimbabwean children. Annals of Tropical Paediatrics, Vol. 18, No. 1, (March 1998), pp. 5-12, ISSN 0272-4936 
[3] Bassili, A., Moktar, S., Dabous, N., et al. (2000). Risk factors for congenital heart disease in Alexandria, Egypt. European Journal of Epidemiology, Vol. 16, No. 9, (2000), pp.805-14

[4] Bode-Thomas, F., Okolo, S., Ekedigwe, J., et al. (2003). Paediatric echocardiography in Jos University Teaching Hospital: problems, prospects and preliminary audit. Nigerian Journal of Paediatrics, Vol. 30, (2003), pp. 143-149

[5] Children's HeartLink. (2007). Linked by a common purpose: global efforts for improving pediatric heart health, A report by Children's HeartLink, Retrieved from http://www.childrensheartlink.org/docs/globalreport

[6] Hoffman, J \& Kaplan, S. (2002). The incidence of congenital heart disease. Journal of the American College of Cardiology, Vol. 39, No. 12, Jun 2002, pp. 1890-1900, ISSN 07351097/02/S22.00

[7] Howson, C., Christianson, A and Modell, B. (2008). Controlling birth defects: reducing the hidden toll of dying and disabled children in low-income countries. In: Disease Control Priorities Project, Accessed 22nd July 2011, Available from: http://www.dcp2.org

[8] Ibadin, M., Sadoh, W., Osarogiagbon, W. (2005). Congenital heart diseases at the University of Benin Teaching Hospital. Nigeria Journal of Paediatrics, Vol. 2, (2005), pp. 6-9

[9] Khalil, A., Aggarwal, R., Thirupuram, S., Arora, R. (1994). Incidence of congenital heart disease among hospital live births in India. Indian Pediatrics, Vol. 31, No. 5, (May 1994), pp. 519-527

[10] Leblanc, J. Creating a global climate for pediatric cardiac care. World Journal of Pediatrics, Vol. 5, No. 2, (May 2009), pp. 89-92

[11] March of Dimes. (2006). Global report on birth defects, Accessed 22nd July, 2011, Available from: http:/ / www.marchofdimes.com/globalprograms

[12] Mocumbi, A., Lameira, E., Yaksh, A., Fereira, M., Sidi, D. (2011). Challenges on the management of congenital heart disease in developing countries. International Journal of Cardiology, Vol. 148, (2011), pp.285-288

[13] Park, M. (2007). Pediatric Cardiology for Practitioners, (5 ${ }^{\text {th }}$ edition), Elsevier, ISBN: 978-81312-1304-9, New Delhi

[14] Pezzella , A. (2010). Global aspects of cardiothoracic surgery with focus on developing countries. Asian Cardiovascular \& thoracic annals, Vol. 18, No. 3, 2010, pp. 299-310

[15] Rao, S. (2007). Pediatric cardiac surgery in developing countries. Pediatric Cardiology, Vol. 28, (2007) pp. 144-148

[16] Sadoh, W. (2011). The cost of out-patient management of chronic heart failure in children with congenital heart disease. Nigerian Journal of Clinical Practice, Vol.14, No. 1, (April 2011), pp. 65-69

[17] Saxena, A. (2005). Congenital heart disease in India: a status report. Indian Journal of Pediatrics, Vol. 72, No. 7, (July 2005) pp. 595-598.

[18] Stolf, N. (2007). Congenital heart surgery in a developing country: a few men for a great challenge. Circulation, Vol. 116, pp. 1874-1875, ISSN: 0009-7322

[19] Subramanyan, R., Joy, J., Venugopalan, P., Sapru, A \& al Khusaiby SM. (2000). Incidence and spectrum of congenital heart disease in Oman. Annals of Tropical Paediatrics, Vol. 20, No 4, (Dec 2000), pp 337-341. 
[20] World Bank (2011). World Bank list of economies, In: Changes in country classifications, Accessed 23rd July 2011, Available from: http:/ / www.data.worldbank.org

[21] World Health Organization. (1996). Control of Hereditary Diseases. WHO Technical Report Series 865. WHO, Geneva, Switzerland.

[22] Yacoub, M. (2007). Establishing pediatric cardiovascular services in the developing world: a wake-up call. Circulation, Vol. 116, (2007) pp. 1876-1878, ISSN 0009-7322 


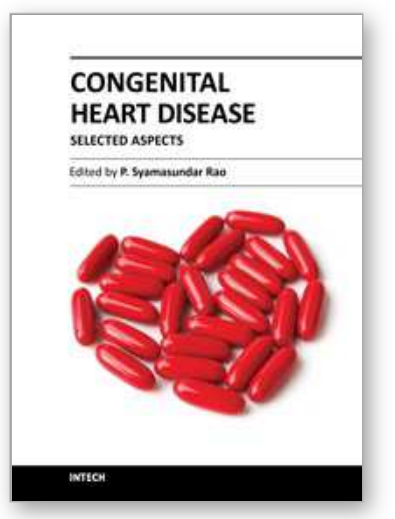

\author{
Congenital Heart Disease - Selected Aspects \\ Edited by Prof. P. Syamasundar Rao
}

ISBN 978-953-307-472-6

Hard cover, 348 pages

Publisher InTech

Published online 18, January, 2012

Published in print edition January, 2012

There are significant advances in the understanding of the molecular mechanisms of cardiac development and the etiology of congenital heart disease (CHD). However, these have not yet evolved to such a degree so as to be useful in preventing $\mathrm{CHD}$ at this time. Developments such as early detection of the neonates with serious heart disease and their rapid transport to tertiary care centers, availability of highly sensitive noninvasive diagnostic tools, advances in neonatal care and anesthesia, progress in transcatheter interventional procedures and extension of complicated surgical procedures to the neonate and infant have advanced to such a degree that almost all congenital cardiac defects can be diagnosed and "corrected". Treatment of the majority of acyanotic and simpler cyanotic heart defects with currently available transcatheter and surgical techniques is feasible, effective and safe. The application of staged total cavo-pulmonary connection (Fontan) has markedly improved the long-term outlook of children who have one functioning ventricle. This book, I hope, will serve as a rich source of information to the physician caring for infants, children and adults with CHD which may help them provide optimal care for their patients.

\title{
How to reference
}

In order to correctly reference this scholarly work, feel free to copy and paste the following:

Fidelia Bode-Thomas (2012). Challenges in the Management of Congenital Heart Disease in Developing Countries, Congenital Heart Disease - Selected Aspects, Prof. P. Syamasundar Rao (Ed.), ISBN: 978-953-307472-6, InTech, Available from: http://www.intechopen.com/books/congenital-heart-disease-selectedaspects/challenges-in-the-management-of-congenital-heart-disease-in-developing-countries

\section{INTECH}

open science | open minds

\section{InTech Europe}

University Campus STeP Ri

Slavka Krautzeka 83/A

51000 Rijeka, Croatia

Phone: +385 (51) 770447

Fax: +385 (51) 686166

www.intechopen.com

\section{InTech China}

Unit 405, Office Block, Hotel Equatorial Shanghai

No.65, Yan An Road (West), Shanghai, 200040, China 中国上海市延安西路65号上海国际贵都大饭店办公楼 405 单元

Phone: +86-21-62489820

Fax: $+86-21-62489821$ 
(C) 2012 The Author(s). Licensee IntechOpen. This is an open access article distributed under the terms of the Creative Commons Attribution 3.0 License, which permits unrestricted use, distribution, and reproduction in any medium, provided the original work is properly cited. 